\title{
Perspective in the History of Science and Technology
}

\author{
Eberhard Knobloch \\ President of the International Academy of the History of Science, Germany \\ Email: eberhard.knobloch@tu-berlin.de \\ Received June $12^{\text {th }}$, 2013; revised July $13^{\text {th }}$, 2013; accepted July $20^{\text {th }}$, 2013
}

\begin{abstract}
Copyright (C) 2013 Eberhard Knobloch. This is an open access article distributed under the Creative Commons Attribution License, which permits unrestricted use, distribution, and reproduction in any medium, provided the original work is properly cited.
\end{abstract}

Dear readers:

History of science and technology is certainly a flourishing discipline. In 2013 the 24th International Congress of the History of Science and Technology takes place in Manchester. More than thousand lectures will be given, especially the traditional Academy lecture of the International Academy of the History of Science by the internationally renowned historian of science Julio Samsó from Barcelona. The European Society of the History of Science attracts an increasing number of members, its congresses an increasing number of participants. The next congress will take place in Lisbon in 2014.

There is a continuously increasing number of journals that publish new insights and results of historians of science among them being the promising Advances in Historical Studies. Their editorial board consists of fourty-four members coming from eighteen different countries thus reflecting the extreme internationality of the whole enterprise.

The same is true of the subject dealt with by historians of science and technology who combine their efforts in order to investigate interdisciplinary and interdepartmental research questions, ways of thinking, ways of justifying or securing newly gained knowledge like analogy, demonstration, visualization.

A special task of our discipline is the appropriate realization of editions and translations that enable scientists to study scientific influences, receptions, networks and to evaluate scientific achievements. I would like to mention some examples. The Leibniz edition is realized by four teams in Berlin, Hannover, Münster, and Potsdam (http://www.leibniz-edition.de). Six of the presumably thirty volumes covering Leibniz's mathematical studies (series 7) have been published up to now, one of presumably eight or nine volumes covering his studies regarding natural sciences, medicine, technology (series 8) has appeared up to now. An incredible richness of new insights is gained by every new volume.

The same can be said about the volumes that will contain the correspondences of Alexander von Humboldt. In 2013, at least four volumes can be expected, namely Humboldt's correspondence with the famous astronomer Franz Encke, with the French natural scientist Jean-Baptiste Boussingault, with the Prussian king Frederic William IV. A fourth volume will explain Humboldt's relations with more than hundred artists that is based on his correspondences with these contemporaries.

In Rome Giorgio Israel has established an international group of editors who prepare an edition of Luigi Cremona's correspondence, that is, of one of the most famous Italian mathematicians of the 19th century. The edition will appear within the book series De diversis artibus of the International Academy of the History of Science.

Other international cooperations are planned in order to publish the huge correspondence of the astronomer Johannes Hevelius whose letters are mainly kept in Parisian archives. I am convinced that these scientific enterprises will significantly contribute to the advances in historical studies and that the new journal carrying exactly this name will strongly profit by this development.

May 2013 